\title{
Conceptual model for a study of emotional health of the young people in the conditions of the coronavirus pandemic
}

\author{
Oleksiy Chebykin ${ }^{1}$, Olena Kosyanova ${ }^{1}$, and Alina Vinkovska ${ }^{1, *}$ \\ ${ }^{1}$ South Ukrainian National Pedagogical University named after K. D. Ushynsky, 26 Staroportofrankivska Str., Odessa, 65000, Ukraine
}

\begin{abstract}
The article reports the results of study of the psychological aspects of the emotional health of the youth in educational process in the coronavirus pandemic conditions. In recent years, the psychological aspects of the personality emotional health are widely studied. In the last studies emotional health is considered on the base of individual characteristics of personality, such as anxiety, aggressiveness, etc. In the presented work the most representative factors linked to the quarantine influence on emotional sphere of personality are taken into account. We ascertain that there are not only negative but also positive tendencies in the influence of pandemic conditions on the emotional state of people. In this work, a conceptual model for the step-by-step study of the psychological aspects of emotional health is proposed. In the process of this study such psychological components of an emotional health as ontogenesis, emotiogenicity, significance, and severity are introduced. The emotional state of students is an important factor determining the effectiveness of the educational process. Accounting for the emotional state can be carried out on the basis of various approaches. This paper focuses on the psychological aspects of the emotional health of students in pandemic conditions.
\end{abstract}

\section{Introduction}

The challenges that faced humanity at the end of 20th century influenced significantly on the emotional state of people. The world has found itself in new conditions associated with the processes of globalization, sharply increased flows of information, military conflicts, environmental and man-made disasters. The global pandemic (COVID-19) that is spreaded to hundreds of countries was also superimposed on all these processes [1-5].

It is clear that long-term quarantine restrictions have had negative impacts on the psychoemotional state of people. Scientists and social workers of many countries state significant increases in stresses, family conflicts, and suicidal cases last year [6-12]. The problem of emotional health of people who have contracted coronavirus and are undergoing treatment or have recovered yet unexplored enough.

Some authors indicate that along with emotionally negative effects the positive ones also occur during the quarantine period. These data are summarized in table 1 [13-17]. The quarantine restrictions associated with the transition to distance learning seriously affect the emotional state of students. For example, an excessive use of gadgets leads not only to stressfulness but also to emotional addiction. These effects require in-depth study especially in pandemic conditions.

It is important to know how stable the emotional changes and how they manifest in the educational process. Now it is relevant to provide special studies not only to reveal undesirable effects in emotional health, but to search

*e-mail: alina.vinkovskaya@gmail.com for corrective and preventive measures to improve and to stabilize it.

Manifestation of negative and positive effects in the emotional sphere of the personality in conditions of quarantine:

- Positive:

- Emotional activation of people to achieve life goals

- The emergence of a more attentive attitude of the person to his emotional state

- The inclusion of physical exercise in the individual's daily schedule, etc.

- Activation of volitional efforts to find effective ways to overcome conflicts

- The emergence of useful experience in adjusting the intended goals, taking into account the complicated circumstances

- Reassessment and rethinking of life values

- Increased attention of the individual to his spiritual development etc.

- Negative:

- The emergence of negative emotional states in the form of anxiety, frustration, depression, of unfounded experiences

- Increase of emotional sensitivity to the stressful and post-stress states

- Emergence of emotional Internet addiction

- Manifestation of emotional discomfort linked to weight gain 
- Emergence of emotional instability in overcoming different conflicts

- Manifestation of inadequate self-esteem against the background of emotional stress

- Manifestation of emotional exhausting from various restrictions, etc.

At present, the ideas of emotional health from the standpoint of mental phenomena have not been considered on the serious level. The analysis of different views concerning the problem of the psychological aspects of emotional health has showed the need to build a conceptual model for its study. In this work we do an accent on the case of the emotional state of students in the conditions of the coronavirus pandemic. Wherein, we proceed from the consideration of an emotional health from the standpoint of mental phenomena.

\section{Methods and materials}

In the study, the authors proceeded from the fact that the influence of psychological factors on the emotional health of a person is significantly manifested in extreme conditions.

Research concerning the psychological aspects of students' emotional health is especially important. It is this age of people that determines the successful formation of their emotional maturity. It is necessary to study the psychological reactions of young people to extreme situations, which of course include the COVID-19 pandemic. In the mainstream of our research, it becomes possible to establish a connection between emotional maturity and the manifestation of psychological characteristics that determine the emotional health of students. It is natural to assume that the level of emotional maturity significantly determined psychological characteristics and the emotional health of young people.

The COVID-19 pandemic certainly belongs to such conditions. Therefore, a test questionnaire was drawn up to conduct an experiment with students, which was supposed to show which psychological characteristics of the personality are most affected by the conditions of the pandemic. The research was carried out in three stages.

\subsection{Description of research scheme}

At the first stage, a special course was developed to familiarize students with the main psychological components of emotional health, since such a discipline is not provided for in the curriculum.

The course generalizes the understanding of emotionally mature personality. Low level of emotional maturity is characterized by the absence or insufficient formation of emotional reactions to the world around. The essence, content and structure of emotional maturity are considered as an integrative quality of personality, which characterizes the degree of development of the emotional sphere at the level of the adequacy of emotional response in certain socio-cultural conditions. The concept of emotional health is understood in connection with psychological factors that determine it. Each of the psychological components of emotional health, integrating with other properties and processes, is reflected on both the conscious and subconscious levels of the human psyche.

The psychological components of personality's' emotional health affected by the pandemic COVID-19 are characterized.

This first stage was intended to help students to understand and answer the testing questions.

At the second stage, a testing experiment was carried out on the basis of a compiled questionnaire. The questionnaire consisted of 40 questions. Here are some examples of these questions: "Has your overall emotional health changed as a result of the COVID-19 pandemic?

Do you notice a gradual change in your emotional health during the quarantine?

Do you notice the influence of hereditary factors on the change in your emotional health during the quarantine?

Are there any distinctive features of the influence of various destructive factors and stresses on your emotional health due to the pandemic?

What psychological components of your emotional health have been most affected by the pandemic (emotional stability, anxiety, depression, etc.)?

Has your performance changed during the pandemic?

Has the emotional perception of lectures changed in the course of online learning?

How did the quarantine regime affect your attitude towards colleagues?

How has the quarantine regime affected your attitude towards your friends?

Did you manage to do anything significant in your work or creativity during the quarantine?

Have you noticed changes in the behavior of the people around you during the quarantine?"

At the third stage, the test results were analyzed, and thus it was revealed which psychological components of emotional health, based on the data obtained from the respondents, are most susceptible to the impact of the conditions of the COVID-19 pandemic.

It can be assumed that these components are significant in the study of the emotional health of a person. Taking into account also existing ideas in this area of [18-21], a conceptual model was developed for a study of the psychological aspects of the emotional health of a person.

\subsection{Description of experiment and results}

Students of the Faculty of Psychology of South Ukrainian National Pedagogical University named after K. D. Ushynsky participated in the research. The research group was represented by 123 students aged 17-24 years old (42 - boys, 81 - girls). After completing the course "Psychological Foundations of Emotional Health", specially read to students to prepare them for the experiment in the classroom conditions, students were asked to answer testing questions [22].

The students had ample time and favorable conditions to thoughtfully answer the questions. 
Table 1. Test results of the testing experimental group of students

\begin{tabular}{ll}
\hline $\begin{array}{l}\text { The main psychological } \\
\text { components of students' } \\
\text { emotional health affected }\end{array}$ & $\begin{array}{l}\text { Percent } \\
\text { of students }\end{array}$ \\
by the pandemic COVID-19 & \\
\hline
\end{tabular}

\begin{tabular}{lc} 
Hereditary factors & 31 \\
$\begin{array}{l}\text { Depressive states } \\
\text { Emotional stability, a sense of comfort, } \\
\text { well-being }\end{array}$ & 25 \\
$\begin{array}{l}\text { Self-regulation capabilities,training } \\
\text { effectiveness, recreational and } \\
\text { recovery abilities }\end{array}$ & 14 \\
$\begin{array}{l}\text { Emotional addictions, emotional deviations } \\
\text { Ema }\end{array}$ & 10 \\
\hline
\end{tabular}

Due to quarantine restrictions, the study was carried out online.

The results of testing are presented in table 1. In Table 1 one can see that students turned out to be distributed in a certain way with respect to the influence of psychological factors on their emotional state during a pandemic [23].

The test results showed that respondents consider hereditary factors and possible depressive states to be the most susceptible to the influence of the conditions of the pandemic. Emotional deviations characteristic of a given personality change insignificantly. It also found that differences between these changes for boys and girls are hardly noticeable. In the case of boys, this influence is more pronounced [24].

Table 1 shows how students are distributed depending on the influence of various psychological factors on their emotional state in connection with pandemic conditions. These results focus on the importance of taking certain psychological aspects into account in the study of emotional health.

\section{Results}

Based on the test results, as well as on publications [2224], we have developed a conceptual model for the study of the psychological aspects of the emotional health of a person.

Part of the research in the framework of this model is already underway.

However, it is supposed to use this model for a comprehensive and versatile study of psychological aspects of the emotional health of a person in the future.

\subsection{Description of the model}

The model for studying the influence of various psychological components on the emotional health of a person was formed on the basis of the test results and analysis of the literature available in this area. Emotional health is considered as a state of the sensory sphere of personality, which changes from the positive to the negative state.

There are a wide range of psychological characteristics of the emotional sphere of a person. By the degree of importance (i.e., their role in determining the emotional health of an individual) they can be arranged in the conditional scale from the maximum positive to relatively negative characteristics, which even lead to certain deviations from the normal state. Such a scale will be formed in the course of the further research based on the proposed model (figure 1).

The proposed model includes five areas of research.

At first, it involves taking into account the age-specific characteristics of the emotional sphere of the individual.

The second direction includes factors that affect the emotional health in connection with physiological features of a person in various conditions of activity. The factors in this case depend on the inherited features of emotional health, as well as diseases and physical trauma. Also, here we refer to studying a special class of stresses arising from changes in social conditions (conflicts, psychogenic circumstances, including catastrophes, epidemics, etc.).

The third direction is "Specific properties and states characterizing emotional health". This includes such properties as emotional stability, emotional maturity, etc. and such states as emotional exhaustion, anxiety, emotional ambivalence, depression, etc.

The fourth direction "Some features of the not usual emotional state" includes emotional accentuations (emotional infantilism, emotional deviations, etc.).

The fifth direction (search and development of corrective methods) includes psychological and sociopsychological techniques and training.

These five directions (figure 2) are partially reflected in works [11, 25-29], however, they are detailed and modified in the presented model.

We included these five areas of research in our model, based on the students' test results and taking into account their age features. At this age, the influence of external conditions on the psychological state of the individual is most pronounced. At the same time, we proceeded from research that is already being carried out in some of the indicated directions. It is clear that in the future, in the process of implementing this model, branches of these directions may appear and new ones may arise. However, the proposed model will serve as the basis for a broad study of an important problem related to the psychological aspects of the emotional health of an individual.

It is understood that a study of emotional health should be carried out in parallel at the neurological, psychiatric and other levels [17, 30, 31]. Using these additional results will provide to solve more problems connected with psychological aspects of emotional health.

In the description of emotion one focuses primarily on emotion as a reaction. However, to account fully for emotional nature, it is necessary to understand the chain of events that leads up to this reaction. They include processing and interpreting external (visual, auditory or other types of perception) and internal (thought) stimuli. An- 


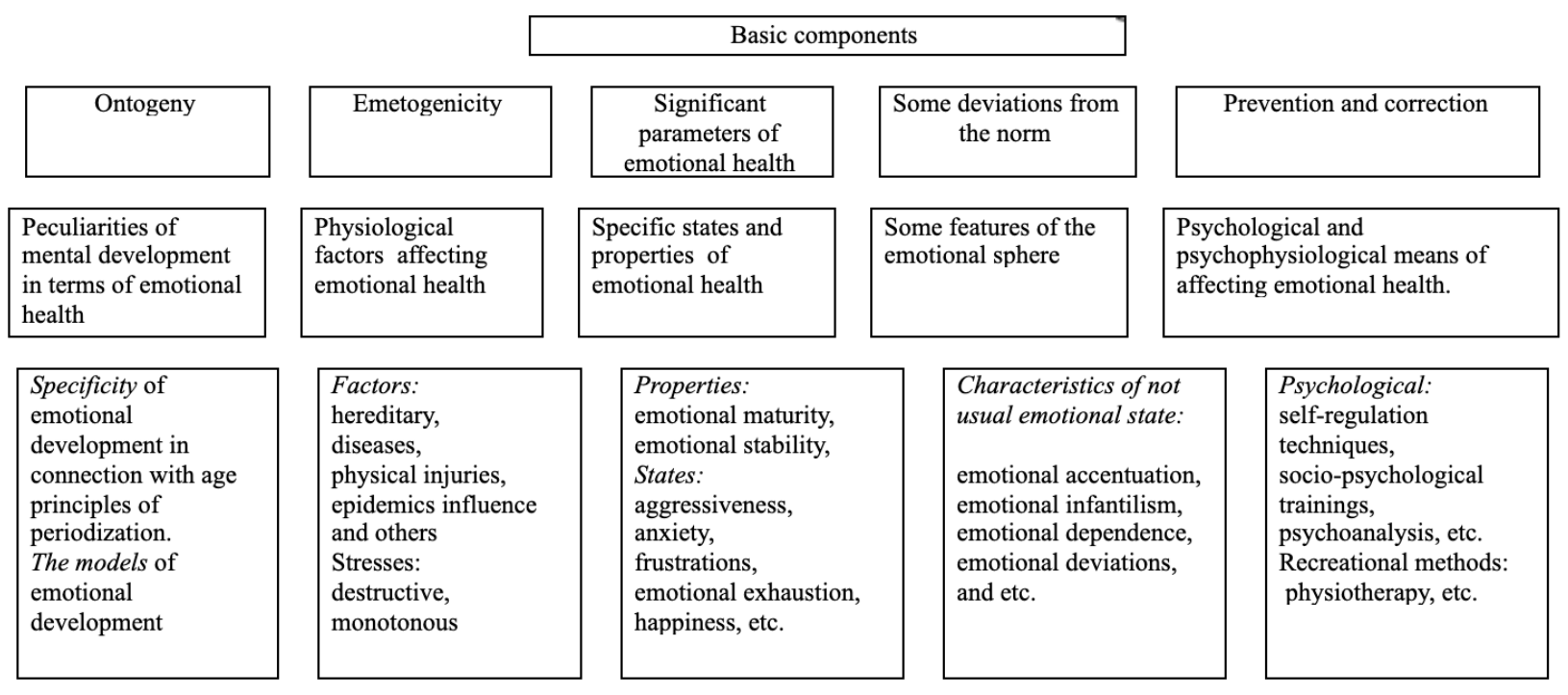

Figure 1. Conceptual model of a time-phased study of psychological aspects of emotional health

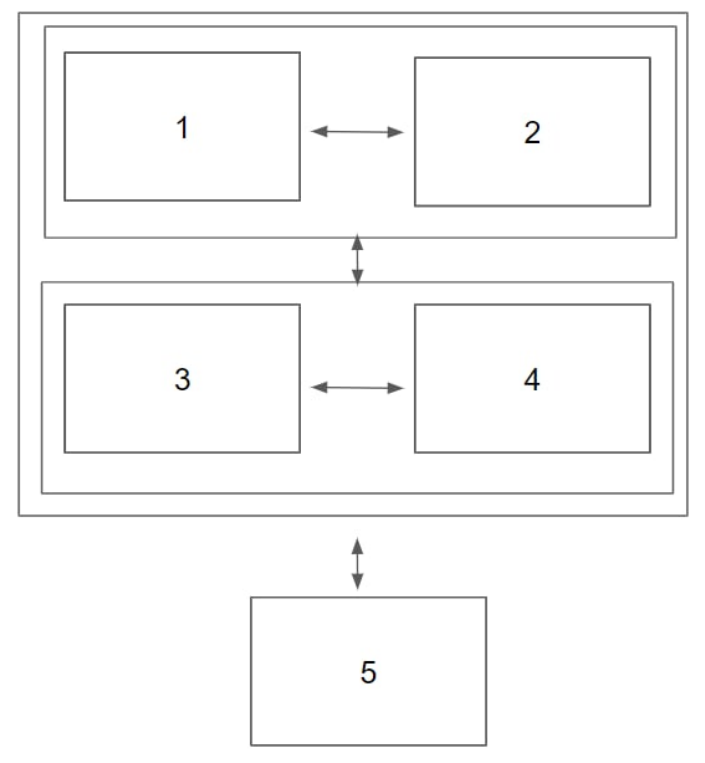

Figure 2. A scheme for coordination of research in five directions

other important aspect of emotion that goes beyond emotional reaction is emotional understanding, which refers to our ability to recognize emotions in ourselves and in others. In general, both aspects determine the emotional state and emotional health of an individual [29, 32].

A thorough understanding of emotions in neurological disease will need to take into account different aspects of emotional state, and different types of emotions. Emotional models that identify the psychological and neuroanatomical processes of the emotional system have been already developed and should be used in future studies. An important question for example is an understanding of the ways in which emotional systems are disturbed with brain injury. It is necessary to underline the organizing functions of emotion, and understand that emotions are multifaceted responses involving thoughts, visceral sensations and facial and bodily reactions.

When emotions are strong, these reactions can occur very quickly, and in a coordinated fashion. This allows emotions to be implemented efficiently in response to critical situations. Some aspects of emotion are innate, and some are more variable across individuals. It is understood that a study of emotional health should be carried out in parallel at the neurological, psychiatric and other levels [18, 30, 31].

Using these additional results will provide more problems connected with psychological aspects of emotional health.

In the description of emotion one focuses primarily on emotion as a reaction. However, to account fully for emotional nature, it is necessary to understand the chain of events that leads up to this reaction. They include processing and interpreting external (visual, auditory or other types of perception) and internal (thought) stimuli.

Another important aspect of emotion that goes beyond emotional reaction is emotional understanding, which refers to our ability to recognize emotions in ourselves and in others. In general, both aspects determine the emotional state and emotional health of an individual [24 25]. A thorough understanding of emotions in neurological disease will need to take into account different aspects of emotional state, and different types of emotions. Emotional models that identify the psychological and neuroanatomical processes of the emotional system have been already developed and should be used in future studies. An important question for example is an understanding of the ways in which emotional systems are disturbed with brain injury.

It is necessary to underline the organizing functions of emotion, and understand that emotions are multifaceted 
responses involving thoughts, visceral sensations and facial and bodily reactions. When emotions are strong, these reactions can occur very quickly, and in a coordinated fashion. This allows emotions to be implemented efficiently in response to critical situations. Some aspects of emotion are innate, and some are more variable across individuals.

A model of emotional processes must account for the fact that emotional reactions are typically adjusted to match situational demands. These processes, and other types of regulation, are important component of the brain's emotional processing systems, and may be particularly relevant to human emotional processing. The changes in all of e aspects of emotional functioning, including emotional reactions, emotion regulation, appraisal, emotional understanding, and empathy, are found in a number of neurological diseases. Therefore studies of neurological disease would be well served to consider the full range of emotional functioning.

The boundaries between the various aspects of emotional functioning can be blurry and the interactions among them are complex. The key brain regions are participating in multiple aspects of emotional functioning.

It is understood that a study of emotional health should be carried out in parallel at the neurological, psychiatric and other levels [26 - 30]. Using these additional results will provide to solve more problems connected with psychological aspects of emotional health.

\section{Discussion}

The presented model indicates a sequence of steps to research psychological components of emotional health. We conducted an experimental study of the influence of extreme conditions caused by the COVID-19 pandemic on the manifestation of psychological components of students' emotional health.

To obtain the most reliable data in the testing process, a preliminary stage of preparing students for testing was carried out, which consisted of developing a course of lectures "Psychological Foundations of Emotional Health" and mastering this course by students.

It is clear that under normal conditions the manifestation of the psychological components of emotional health may differ. However, it is important to know which of the above components are more and which are less sensitive to changes in environmental conditions. A personality is constantly in changing conditions. Stressful situations constantly arise in life. Therefore, the information obtained in our experiment provides an orientation towards the interaction of the main psychological components of emotional health in real life conditions

In these conditions, the psychological characteristics of a person are manifested, which characterize his emotional health.

The study of these features is important for solving many practical problems in human life.

At the same time, the psychological aspects of the emotional health of an individual in the specific conditions of the COVID-19 pandemic are of independent interest. Research in this direction will continue.

Young adults have experienced a number of pandemicrelated consequences, such as closures of universities and loss of income that may contribute to poor mental health. During the pandemic, a larger than average share of young adults) report symptoms of anxiety and/or depressive disorder. Compared to all adults, young adults are more likely to report substance use. Prior to the pandemic, young adults were already at high risk of poor mental health and substance use disorder.

\section{Conclusion}

1. Various aspects of the impact of the COVID-19 pandemic on the emotional health of people are discussed. It was emphasized that there are also positive factors of the effect of quarantine on the emotional state of people. These positive factors of the influence of extreme conditions on the psychological state of people, as a rule, are not taken into account. However, it is advisable to take them into account in the general assessment of the conditions of the pandemic

2. The questionnaire, designed to test students, was aimed at finding out how students feel the impact of the pandemic on their emotional state with an emphasis on psychological factors. Taking into account the age characteristics of the respondents and their increased sensitivity to extreme external conditions, the test results were used to construct a conceptual model to study the psychological aspects of the emotional health of an individual.

3. In the course of the research, special preparation of students for testing was provided. The research design included a preparatory stage, when a special course was read to students to prepare them for testing.

4. Analysis of the results of testing the respondents showed that the influence of the extreme conditions of the pandemic is felt to the greatest extent depending on hereditary factors and depressive conditions characteristic of a person. This result does not depend on the gender differences of the person. This result has an independent meaning and is the subject of further study. This does not depend on the gender differences of the person.

5. Emotional dependencies and emotional deviations of the personality do not undergo significant changes in a pandemic. This result also does not depend on the gender differences of the person.

6. The results of the experiment, as well as the results of other authors, formed the basis of the conceptual model. It is assumed that the proposed model will be used to conduct research in a wide range of psychological aspects of the emotional health of a person.

The authors thank Prof. A. E. Kiv for a helpful discussion. 


\section{References}

[1] A. Kiv, P. Hryhoruk, I. Khvostina, V. Solovieva, V. Soloviev, S. Semerikov, CEUR Workshop Proceedings 2713, 1 (2020)

[2] V.N. Soloviev, A.O. Bielinskyi, N.A. Kharadzjan, CEUR Workshop Proceedings 2832, 24 (2020)

[3] A. Bielinskyi, I. Khvostina, A. Mamanazarov, A. Matviychuk, S. Semerikov, O. Serdyuk, V. Solovieva, V. Soloviev, IOP Conference Series: Earth and Environmental Science 628 (2021)

[4] S. Semerikov, H. Kucherova, V. Los, D. Ocheretin, CEUR Workshop Proceedings 2845, 22 (2021)

[5] M. Velykodna, Psychodynamic Practice 27, 10 (2021)

[6] A.Z. Spector, Achieving Application Requirements (Association for Computing Machinery, New York, NY, USA, 1990), p. 19-33, ISBN 0201416603, https://doi.org/10.1145/90417.90738

[7] S. Schäfer, M. Sopp, C. Schanz, M. Staginnus, A. Göritz, T. Michael, Psychotherapy and Psychosomatics 89, 386 (2020)

[8] L. Tarabakina, Theory and practice of social development 8 (2015)

[9] J. Das-Munshi, D. Goldberg, P.E. Bebbington, D.K. Bhugra, T.S. Brugha, M.E. Dewey, R. Jenkins, R. Stewart, M. Prince, British Journal of Psychiatry 192, 171-177 (2008)

[10] J. Lai, S. Ma, Y. Wang, Z. Cai, J. Hu, N. Wei, J. Wu, H. Du, T. Chen, R. Li et al., JAMA Network Open 3, e203976 (2020)

[11] V. LoBue, K. Pérez-Edgar, K.A. Buss, eds., Handbook of Emotional Development (Springer, 2019)

[12] H.M. Bai, ComFin Research 8, 8 (2020)

[13] M. Pierce, H. Hope, T. Ford, S. Hatch, M. Hotopf, A. John, E. Kontopantelis, R. Webb, S. Wessely, S. McManus et al., The Lancet Psychiatry 7, 883 (2020)

[14] M. Di Giuseppe, S. Zilcha-Mano, T.A. Prout, J.C. Perry, G. Orrù, C. Conversano, Frontiers in Psychiatry 11, 1022 (2020)
[15] S. Khan, R. Siddique, H. Li, A. Ali, M.A. Shereen, N. Bashir, M. Xue, The Journal of Global Health 10, 010331 (2020)

[16] L.K. I. Faustova, J. Psychology of education in a multicultural space 68 (2019)

[17] S. Mukhtar, International Journal of Social Psychiatry 66, 512 (2020), pMID: 32434402, https://doi.org/10.1177/0020764020925835

[18] J. Xiong, O. Lipsitz, F. Nasri, L. Lui, H. Gill, L. Phan, D. Chen-Li, M. Iacobucci, R. Ho, A. Majeed et al., Journal of affective disorders 277, 55-64 (2020)

[19] A. Kichuk, Psychological Prospects Journal p. 139-151 (2019)

[20] J. Forgas, Ph.D. thesis (2009)

[21] L.P. Zhuravlyova, Nauka i osvita 3, 36 (2010)

[22] A. Chebykin, Ph.D. thesis (1992)

[23] O. Chebykin, O. Kosianova, Deceitfulness according to the indicators of emotional maturity methodology and polygraph examination (2017), https://scienceandeducation.pdpu.edu.ua/ en/articles/2017-7-doc/2017-7-st4-en

[24] O.L. Goncharova, Psychology of aggressive behavior. Study guide (2012)

[25] A. Horwitzand, T. Scheid, Handbook for the Study of Mental Health: Social Contexts, Theories, and Systems (1999)

[26] O. Chebykin, Stanovlennia emotsiinoi zrilosti osobystosti (Formation of emotional maturity of the individual) (Odessa, 2009)

[27] N. Lee, B. Kinder, Comput. Entertain. 3, 4 (2005)

[28] M. Landow, Stress and Mental Health of College Students (2006)

[29] H. Naar, F. Teroni, The Ontology of Emotions (2017)

[30] W. Karwowski, ed., International Encyclopedia of Ergonomics and Human Factors (Routledge, 2006)

[31] D. Whiting, Emotions As Original Existences: A Theory of Emotion (Palgrave Macmillan, 2020)

[32] J.M. Fegert, B. Vitiello, P.L. Plener, V. Clemens, Child Adolesc Psychiatry Ment Health 14, 20 (2020) 